\title{
Multi-Disciplinary Teams and Collaborative Peer Learning in an Introduc- tory Nuclear Engineering Course
}

Samuel A. Heider, U.S. Military Academy

BA Physics from the Universty of Nebraska at Lincoln, 2004 PATRIOT Missile system Fire Control Officer 2004-2007, PATRIOT Fire Direction Center Officer 2007, BCT Company Commander 2007-2008, Validation Transition Team Leader (AFG) 2008-2009, Engineer Captain Career Course 2010 MS Nuclear Engineering from Kansas State University, 2012 Instructor United States Military Academy 2012-Present

Col. Bryndol A. Sones, U.S. Military Academy

Dr. Brian E. Moretti, Department of Physics and Nuclear Engineering 
Multi-Disciplinary Teams and Collaborative Learning in an Introductory Nuclear Engineering Course

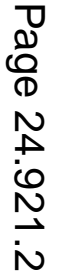




\begin{abstract}
:
Employers listed teamwork, critical thinking, analytical reasoning, and communication as the most highly sought after employee skills (Peter D. Hart Research Associates, Inc., 2006). For engineering institutions these skills are certified, in part, through ABET accreditation and are tested through Student Outcomes including, 'an ability to function on multi-disciplinary teams' and 'an ability to communicate effectively'. Dr. Robert Beichner's work in the 'SCALE-UP' program at North Caroline State University has highlighted the effectiveness of using small groups instead of large groups in lecture halls to encourage active collaborative learning in the classroom; many others have also touted the importance of collaborative learning. In light of these best practices, multidisciplinary teams at West Point were formed in a Introduction to Nuclear Engineering course from students majoring in engineering, science disciplines, and those in non-technical majors. The intention was to incorporate collaborative learning, and to meet institutional core engineering requirements. Students within each multi-disciplinary team benefit from peer learning in collaborative settings where students share understanding by teaching their peers and by being taught by their peers. These multi-disciplinary team assignments last for the entire semester. Peer learning in a collaborative environment forges teamwork within multi-disciplinary teams, and the products delivered demonstrate effective communication of course concepts. The team members have shared responsibilities for presenting solutions to design problems assigned to the team and for preparing blocks of instruction presented during course lecture periods. Students were required to report their own involvement in team work and to rate their fellow team members' level of participation and contribution. Additionally, students rated the effectiveness of their collaborative learning sessions. Future work should include more collaborative exercises within the classroom as well as a control group for performance comparison.
\end{abstract}




\section{Introduction:}

Every engineering educational institution strives to produce engineers who are prepared to enter an ever changing employment market. Engineers strive to be proficient in their engineering discipline as well as all other areas that may help to determine their marketability as an engineer. To ensure that an institution is preparing its student for future employment, accreditation is often sought through organizations such as ABET. Accreditation helps to ensure that an institution is dedicated to producing graduates who are prepared for employment in industry, research, teaching, and government.

Engineers acquire and hone many skills while pursuing their engineering degrees, but it is often skills that are not specifically engineering skills that are most desired by employers. According to Peter D. Hart Research Associates, Inc. The most highly sought after employee skills are teamwork, critical thinking, analytical reasoning, and communication. ${ }^{1}$ For ABET accredited institutions these abilities are certified through Student Outcomes including, 'an ability to function on multi-disciplinary teams' and 'an ability to communicate effectively' (ABET criterion 3d and 3g). ${ }^{2}$ However, assessing a student's ability to work on a team and to communicate effectively is often difficult in traditional classroom settings.

Collaborative learning, for the purpose of this paper will mirror those of Göl and Nafalski as written in their award winning paper "Collaborative Learning in Engineering Education"; "Collaborative learning is increasingly recognised as giving students an opportunity to engage in discussion and to exercise a positive influence on the group's learning outcomes by assuming responsibility for their own learning. Critical thinking and reflective evaluation are implicit in the approach." 3 While many tout the advantages of collaborative learning: "Results indicate that active or collaborative methods produce both statistically significant and substantially greater gains in student learning than those associated with more traditional instructional methods."4 Others have found difficulty in the implementation of collaboration in engineering and math courses, "Students refuse to participate, or only participate to the extent required." Collaborative learning presents any engineering educator with an opportunity to engage students with problems that require deep learning and knowledge synthesis, and utilize peer learning. This paper will investigate the effects of using peer learning within multi-disciplinary teams from the perspective of the student by collecting responses from students to questions presented at the end of a one semester 'Fundamentals of Nuclear Engineering' course.

II Methods:

All 51 survey respondents were Cadets at the United States Military Academy and primarily first semester juniors with majors including Nuclear, Chemical, and Mechanical Engineering, as well as English and Political Science. From this diverse field teams of three to four were chosen at random so that team make-up was truly multi-disciplinary. The definition of a 'multi-disciplinary team' is not defined by ABET, so in the context of this study a habitual team formed of members from different academic disciplines is considered a 'multi-disciplinary team'. Each multi-disciplinary team met at times and locations set by the team members as needed to fulfill course assignments.

Teams were assigned extension problems that were more complex than traditional homework problems, requiring the use of multiple course concepts, and culminating with graded written reports. Additionally, teams were assigned topics to develop and present in-class 
presentations during the semester. These presentations supported lesson learning objectives and were graded by the instructor. Each presentation was approximately seven minutes in length, utilized visual aids developed by the team, and included the requirement that each student participate in the oral presentation.

The United States Military Academy diligently works to maintain a low student-toinstructor ratio. In the 'Fundamentals of Nuclear Engineering' course, this ratio was 17 $\pm 1: 1$. This relatively low ratio kept the instructor grading load manageable because there were only five teams per class and no more than two classes per instructor. This is important because of the number and length of reports and presentations requiring grading to support the multidisciplinary team approach to learning. However, there were difficulties in determining precisely how much each student was contributing to the team, as all students on a team received the same grade on all reports and presentations. The semester end survey dealt with this issue by providing students with the opportunity to rate how well their team worked together to accomplish assigned tasks. Individual team members were also required to provide peer ratings for each member of the team, to include themselves. These were collected via paper submission by the instructors. These peer ratings are not included in this study, but provided the instructors with insight into the contribution of each team member during the semester.

At the completion of the course, student responses were solicited in an online survey format regarding their experience while working in a multi-disciplinary team. Students were required to provide feedback on the extension problems, the in-class presentations, their attainment of Student Outcomes 3d, 3g, and how strongly other students had contributed to their learning in the course. The student responses used a scale of 1 to 5 where, $1=$ "Strongly Disagree”, 2= "Disagree”, 3= "Neutral”, 4= “Agree” and 5= "Strongly Agree”. All 51 students (100\%) completed the survey at the end of the semester. Below are the statements students were presented (hereafter, Statements will also be referenced with a letter, A-K, corresponding to the list below):

A. The extension problems helped me synthesize multiple course concepts while developing a solution to the problem.

B. The extension problems required me to think creatively and critically in order to solve a more complex problem.

C. The group in which I was assigned for extension problems came together as a team to solve the problems and complete the required reports.

D. I contributed to the team effort required to solve the extension problems and prepare the required reports.

E. Preparing for in-class presentations helped me to better understand course material.

F. The in-class presentations required me to think creatively and critically in order to understand the material for presentation.

G. In preparing for in-class presentations my team worked together to ensure everyone understood course concepts and were prepared to present the material orally.

H. I contributed to the team effort required to prepare for the in-class presentations.

I. I am confident in my ability to function on multi-disciplinary teams (Outcome $\mathrm{d}$.

J. I am confident in my ability to communicate effectively (Outcome g).

K. My fellow students contributed to my learning in this course.

III Results 
Extension Problems: Over 78\% of the students responded that they 'agreed' or 'strongly agreed' that the extension problems presented to the teams required synthesis of multiple course concepts while less than $12 \%$ reported that they 'disagreed', or 'strongly disagreed' with Statement A. Interestingly, 78\% also found the extension problems to require creative and critical thinking (Statement B), but those 'disagreeing' or 'strongly disagreeing' fell to just below $8 \%$. Tabulated data is provided in Table 1 below.

\section{Table 1: Student Responses to Statements A-D.}

\begin{tabular}{|c|c|c|c|c|c|}
\hline Statement & $\begin{array}{c}\text { Strongly } \\
\text { Agree }\end{array}$ & Agree & Neutral & Disagree & $\begin{array}{c}\text { Strongly } \\
\text { Disagree }\end{array}$ \\
\hline A & 16 & 24 & 5 & 5 & 1 \\
\hline B & 20 & 20 & 7 & 3 & 1 \\
\hline C & 17 & 23 & 7 & 2 & 2 \\
\hline D & 29 & 21 & 0 & 0 & 1 \\
\hline
\end{tabular}

A relatively small minority, less than $8 \%$, responded with a 'disagree' or 'strongly disagree' with regard to their groups ability to come together as a team to solve the extension problems and complete their report (Statement C). However, this is contrasted by just 2\% who responded in kind to their own participation in their assigned group. Here just one respondent stated that they 'strongly disagreed' that they had contributed to the team effort required to solve the extension problems and prepare the required reports (Statement D). The mean scores, with their uncertainty, are highlighted in Fig. 1. From Fig. 1 it is possible to see that the means for each response was greater than three, a 'neutral' response, but that the uncertainty in the mean for Statement A includes the 'neutral' response score. The means and uncertainty for Statements B-D demonstrate an 'agree' or 'strongly agree' response score.

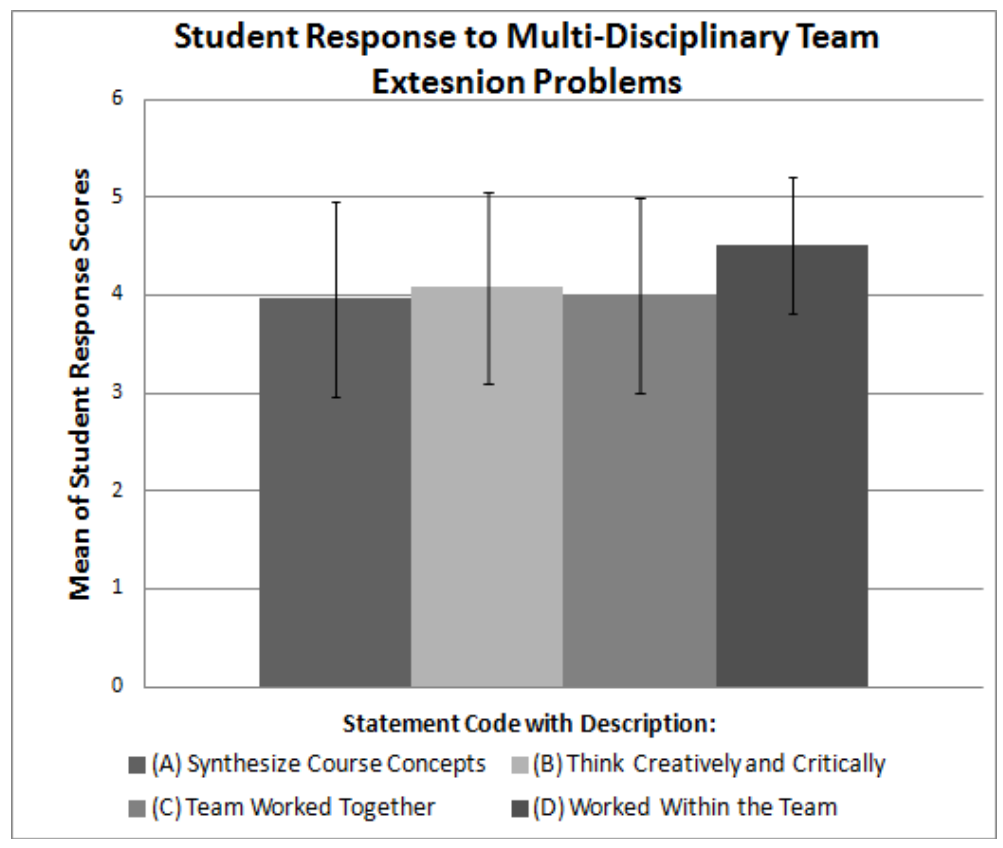

Figure 1: Mean of Student Responses to Statements A-D. 
In-Class Presentations: Nearly $71 \%$ of students 'agreed' or 'strongly agreed' that working in a team to prepare in-class presentations helped them understand course concepts (Statement E). Over 15\% responded with 'disagree' or 'strongly disagree' when presented with a statement about the need for creative and critical thinking when preparing for in-class presentations (Statement F). Responses to Statements E-H are tabulated in Table 2.

Table 2: Student Responses to Statements E-H.

\begin{tabular}{|c|c|c|c|c|c|}
\hline Statement & $\begin{array}{c}\text { Strongly } \\
\text { Agree }\end{array}$ & Agree & Neutral & Disagree & $\begin{array}{c}\text { Strongly } \\
\text { Disagree }\end{array}$ \\
\hline E & 10 & 26 & 11 & 3 & 1 \\
\hline F & 11 & 19 & 13 & 6 & 2 \\
\hline G & 10 & 22 & 10 & 8 & 1 \\
\hline H & 21 & 28 & 2 & 0 & 0 \\
\hline
\end{tabular}

Just over $17 \%$ responded with 'disagree' or 'strongly disagree' concerning the amount of team work needed to complete in-class presentations (Statement G). However, in stark contrast to the nearly over $96 \%$ responded with an 'agree' or 'strongly agree' to their involvement in the team to complete the in-class presentations (Statement $\mathrm{H}$ ). In fact every student felt that he or she contributed to the team effort required to prepare for the in-class presentations to the degree of at least a 'neutral' response on the survey. Figure 2 below, shows that the uncertainty in the means for Statements E-G includes the 'neutral' response. However, for Statement H the mean and uncertainty demonstrate at least an 'agree' response score.

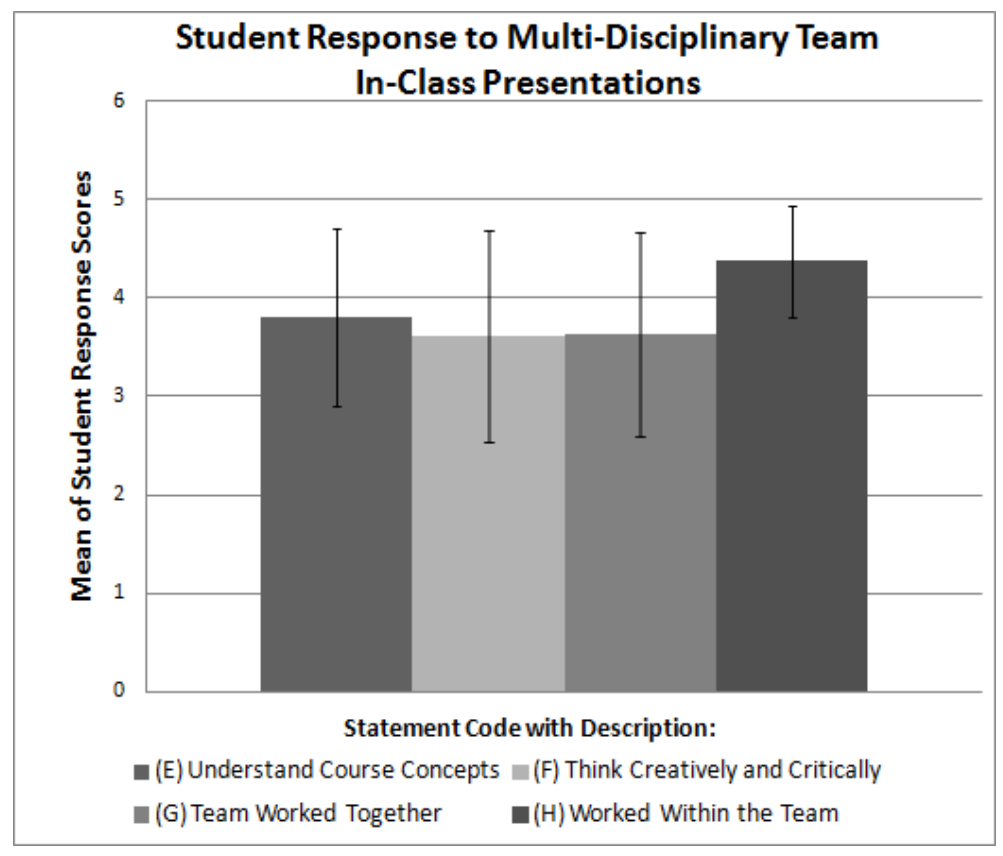

Figure 2: Means of Student Responses to Statements E-H.

Student Outcomes and Peer Contributions: Concerning Student Outcome 3b (Statement I), over $88 \%$ of students felt sure enough of their ability to work on a multi-disciplinary team to 
respond with an 'agree' or 'strongly agree'. Students were also prompted to respond (Statement J) concerning their ability to communicate effectively. For Statement J, over $90 \%$ responded with 'agree' or 'strongly agree'. Over $80 \%$ of students left remarks of 'agree' or 'strongly agree' when prompted with a statement concerning how much they had learned from their peers (Statement K). The responses to Statements I-K are presented in Table 3 and Fig. 3 exhibits the means and uncertainties to the same statements. Figure 3 highlights the fact, for Statements I-K, that none of the uncertainties include the 'neutral' response value and thus it is appropriate to state that students felt confident ('agree') in their ability to work on multi-disciplinary teams, communicate effectively, and that their peers had a positive influence on their learning.

Table 3: Student Responses to Statements I-K.

\begin{tabular}{|c|c|c|c|c|c|}
\hline Statement & $\begin{array}{c}\text { Strongly } \\
\text { Agree }\end{array}$ & Agree & Neutral & Disagree & $\begin{array}{c}\text { Strongly } \\
\text { Disagree }\end{array}$ \\
\hline I & 20 & 25 & 6 & 0 & 0 \\
\hline J & 26 & 20 & 5 & 0 & 0 \\
\hline K & 20 & 21 & 6 & 2 & 2 \\
\hline
\end{tabular}

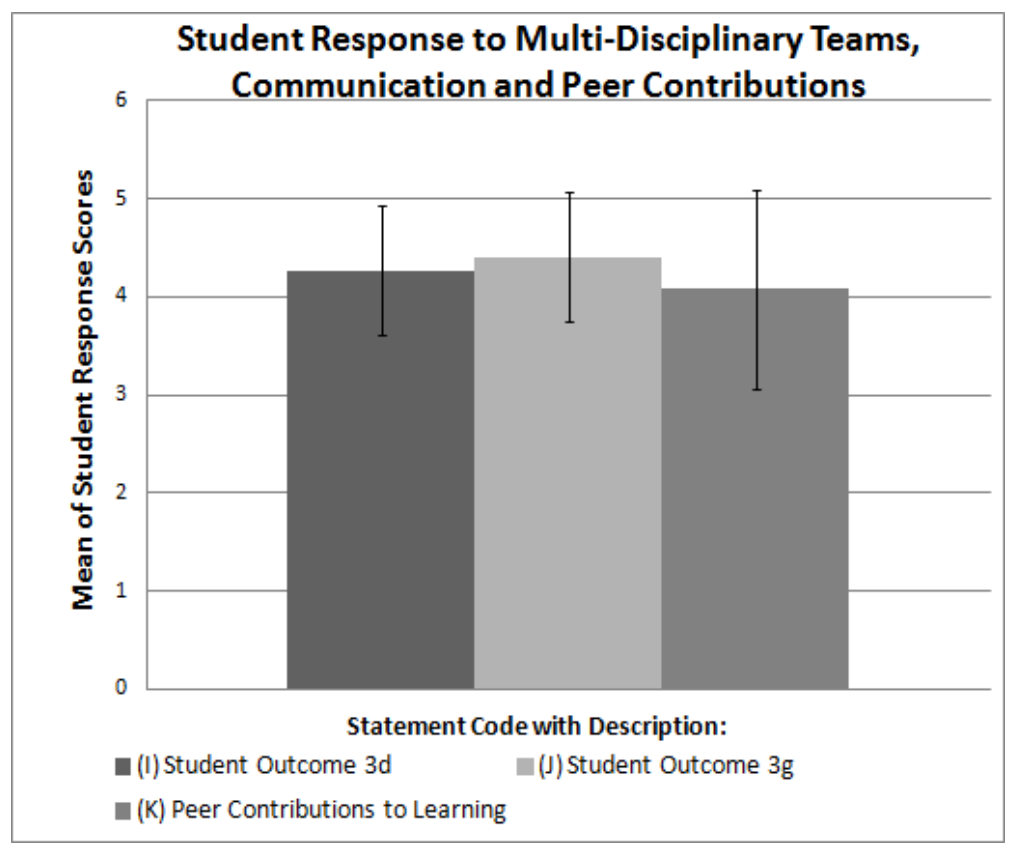

Figure 3: Means of Student Responses to Statements I-K.

IV Conclusions

To meet the demand for engineers who are adept at working on multi-disciplinary teams, are critical thinkers, who have honed their analytical reasoning skills and can communicate both orally and in writing, one must look to the institutions of higher education and their approach to developing these skills within their students. Students, having completed an introductory Nuclear Engineering course, responded that their experience in a multidisciplinary team, brought together to solve extension problems, had challenged them to think creatively and critically and 
had improved their ability to work on a multi-disciplinary team (Statements B and C). However, these same teams cannot be said to have had similar experiences when preparing to instruct their peers on specific aspects of nuclear engineering. For Statements E-G, uncertainly in the responses leaves doubt as to whether requiring students to present course concepts enhanced creative and critical thinking skills, the ability of the team to work together to prepare the presentations, or their understanding of the concepts.

Nearly nine in ten students believed that they could communicate effectively. This follows the trend of responses to the prompts concerning each students contribution to the team effort required to prepare for the in-class presentations and extension problems (Statements D and $\mathrm{H}$ ). However, it seems that this ability was not always enhanced by the team aspects of preparing the in-class briefings (Statements E-G).

A significant trend appears for Responses D, H, I, and J. When comparing the means of these responses to those of most other statements it is evident that students felt that their own abilities and contributions outshone those of their peers. Students ranked their ability to work on a multi-disciplinary team higher than the teams ability to work together to accomplish assigned tasks or even the ability of peers to enhance student learning.

In general, the responses from this group of students indicate that working on multidisciplinary teams using collaborative peer learning helps students think creatively and critically, especially when tackling complex problems, but that more effort is needed to increase the effectiveness of each team when striving to understand and communicate course concepts to peers. Future work should include more collaborative peer learning classroom exercises, enhanced involvement of the instructor in the multi-disciplinary team meetings, using similar feedback mechanisms in later courses for longitudinal comparisons, and possible use of a control group for performance comparison.

\section{References:}

1. Peter D. Hart Research Associates, Inc., (2006). "How Should Colleges Prepare Students To Succeed In Today's Global Economy?,” Based On Surveys Among Employers And Recent College Graduates Conducted On Behalf Of: The Association Of American Colleges And Universities. Available on-line at <http://www.ncsu. aacu.org/leap/documents/Re8097abcombined.pdf>.

2. R.M. Felder and R. Brent. (2003). "Designing and Teaching Courses to Satisfy the ABET Engineering Criteria,” Journal of Engineering Education, 92 (1), 7-25. Available on-line at $<$ http://www4.ncsu.edu/unity/lockers/users/f/felder/public/Papers/ABET_Paper_(JEE).pdf>.

3. Göl, Ö. and Nafalski, A., Collaborative learning in engineering education. Proc. 10th Annual Conf. on Engng. Educ., Bangkok, Thailand, 19-23 (2007).

4. Terenzini, P.; Cabrera, A.; Colbeck, C.; Parente, J.; Bjorklund, S., "Collaborative Learning Vs. Lecture/Discussion: Students’ Reported Learning Gains." Journal of Engineering Education (2001): 123-130. Web.

5. Guzdial, M.; Ludovice, P.; Realff, M.; Morley, T.; Carroll, K.; Ladak, A., "The Challenge of Collaborative Learning in Engineering and Math," Frontiers in Education Conference, 2001. 31st Annual , vol.1, T3B,24-9 vol.1, 2001 